\title{
Word of Mouth Marketing Strategy
}

\author{
Suraj Krishnan \\ Master of Computer Application \\ Veermata Jijabai Technological Institute \\ Mumbai, Maharashtara, India
}

\author{
L. C. Nene \\ Associate Professor \\ Master of Computer Applications \\ Veermata Jijabai Technological Institute \\ Mumbai, Maharashtra, India
}

\begin{abstract}
Word of Mouth Marketing strategy can be defined as "oral, person to person communication between a receiver and a communicator whom the receiver perceives as noncommercial concerning a brand, a product, or a service."

When we consider market analysis and product engineering, this kind of communication tends to be the external factor that is not under control of the company. Although it's not under any influence directly, market management and strategy are *common practices that a company adheres to.
\end{abstract}

While this kind of communication takes place when there are no absolute facts. There are lot of opinions and then emotions, sentiments which influence this decision making. Although this market is not controlled directly under any entity it has an enormous impact when it comes to the way in which the market functions. [3]

This paper is critical observation on how an organization or an entity can use this kind of social media presence to influence their process of new product development. This impact can be negative based on the feedback of the people.[13]

New product development is a part of marketing that this paper is targeting but it can be applied to any other parts of marketing.

For proving this consider an example of a phone manufacturer. The company has a vision to create a phone which will capture the imagination of the market. For which they have information from the market to analyse the data.

In the end the conclusion is what people think about existing market products and what do they need in their new ideal product.

\section{General Terms}

Brand, Online market, Social media, Product development

\section{Keywords}

WoM, Consumer, Digital marketing, Entity, Organization, Social Media.

\section{INTRODUCTION}

\subsection{Word of Mouth}

Word of Mouth, popularly referred to as WoM is essentially, a Customer-to-Customer(C2C) interaction between two customers (or prospective one), it's a type of Lead user analysis[11] wherein one narrates his/ her own experience of using a particular product. In the 1990's the term Word of Mouth became broader term encompassing all the elements of social media and online presence.[2] Though the main principle that people should not be related to company in any shape or form still held.

It's much cheaper compared to traditional marketing. This is because the companies have more reach through social media, online reviews and blogs than traditional source of advertisements.[1]

It's well proven fact that traditional marketing is weak compared to Word of Mouth marketing. This is because of the controlled elements within the traditional marketing. You get to see only the best part of any given product, this makes it difficult for people to trust these kind of advertisements. Instead of those people prefer to have more unfiltered review about the product or service they are interested in. Word of Mouth being uncontrolled environment provides exactly that to consumers. Understanding that is crucial for companies to survive.

It's much more influential as people are more willing to listen to people who are close to them than the traditional media. [13] They are assuming bias (which is bound to happen when company are marketing their product by hiding negative points).[14] It is found that listening to a person online or a person whom we know (and are not related to company) is similar effect to listening to an expert person.

\subsection{New Product Development (NPD)}

Product development, also called new product management, is steps of tasks undertaken to create a new product or service. The objective of product development is to cultivate, maintain and increase a company's market share by satisfying a consumer demand. Not every product will appeal to every customer or client base, so defining the target market for a product is a critical component that must take place early in the product development process. Quantitative market research should be conducted at all phases of the design process, including before the product or service is conceived, while the product is being designed and after the product has been launched.

The fuzzy front end (FFE) defines the steps for New Product Development cycle. This is up to the user how they want to define the intricate of this process. The brief outline of steps defined by FFE are:

- Identification of design criteria

- Idea analysis

- Concept genesis

- Prototyping

- Product development

- Testing

- Commercialisation

\section{THEORETICAL MODEL}

This study encompasses the Word of Mouth in the new product development cycle that an organization follows. This defines the scope as discussion, communication and opinion of people related to a product that they express online.

A new product that company wants to release should have its features and attributes defined. This market research with the 
customer's opinion can help the company to make decision on basis of what has occurred in the past market.

While considering Word of Mouth there are some uncontrolled elements to identify and classify with certain degree of precision. For this purpose, define the problem as a network of entities and the channel through which these entities communicate.

The entities defined in this model are:

- Organization/ Entity: This is the manufacturing organization or the entity itself. There is usually a need to have some past, present condition of the entity defined to understand the path to be taken in the future. This usually contains information about the size of the company, the customer bases, the reach and the market position (shares and market capital)

- Competitors: These are the organizations or the entities that competes with the manufacturing entity. They have similar information to the manufacturing company defined. This information is required to compare and contrast the manufacturing organization from the competitor. If they differ a lot, it would be wise to check whether this strategy would apply to them or not.

- Product: The product is a complex entity which itself contains various attributes that distinguishes itself from one another. When comparing an existing marketing strategy, it is wise to compare the product to check whether they are different from each other. This attributes differ in various domain.

- Customer: The customer is another entity that varies. Understanding the customer from various perspective of age, gender, profession, education, beliefs and expectation is important.

The Word of Mouth is an informal communication that takes place between random people. This is not controlled and differ from traditional marketing in the various factors such as volume, velocity, variety, attitude and completeness etc. To understand this informal structure, define some sources of information

- Social media: The anonymous social media sites which is defined by the exchanges of information by common random people like you and me. This can give an overview of the herd behaviour to expect.

- Survey: This gives some informational background about the customers at the ground level. It gives some valuable information about what people think about the product that is there in the market and what do they expect from an ideal market scenario.

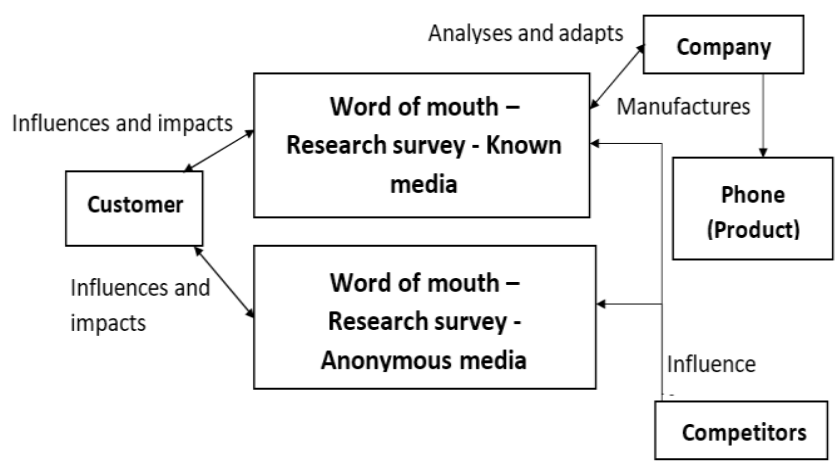

3. APPLICATION / IMPLEMENTATION

This application will find an answer to the question which is part of the proposed hypothesis of various scenarios that can be covered. In the scenario that the company knows the abstract about the product that company want to sell, company knows some information about the customer that will purchase the product. With this information how can company define the product to make and what is the best way to sell that product.

We are using $\mathrm{R}$ studio for analysing the data as it contains lot of data science and visualization related functionalities.

For this purpose, define the source of information as social media site (twitter) and a survey information.

The survey had questions pertaining to

- About their personal information

a. What is your age?

b. What is your gender?

c. What is your qualification?

d. In which domain do you work?

e. Do you own a phone?

- Information related to their phone

a. Which phone do you have now?

b. How did you buy your phone?

c. Where do you look for phone recommendation?

d. Describe what you like about your phone?

e. Describe what you hate about your phone?

- The ideal phone they would like to have

a. What is the ideal price range for your phone?

b. Where do you ideally look for phone recommendation?

c. Features your ideal phone contains?

d. Describe about the features your ideal phone contains?

The application will consider the details of customer as its input. The basic needs or aspiration of the customer should be reflected in the output of this application. This needs and aspiration will be driven by the existing customer data and the closeness of the customer data that the company wants to target.

\subsection{Implementation steps}

The whole process is divided into 6 steps:

- $\quad$ Loading the data in $\mathbf{R}$ studio

For loading the data in $\mathrm{R}$ studio use read_excel functions.

We load 2 data sets to be exact

a. Response of survey

b. Transformed customer data

- Loading the functions in $\mathbf{R}$ studio

In this step the user defined functions are loaded in $\mathrm{R}$ environment. Functions were required to

a. Convert text to lower case

b. Clean the text to trim, remove special characters, escape sequences, stop words and split it on basis of spaces.

c. Compare the text with existing lexicon of positive and negative words.

d. Calculate the score for positive and negative words.

Figure 1: Word of Mouth network 
- Cleaning the source data to fetch the target data and applying the functions in $R$ studio

In this step a customer who defines the target audience was selected and nearest neighbour of that target was fetched on the basis of Mahanalobis distance.[8]

Followed by this the result set is looped upon to fetch the individual records. The individual records contain the text for what the customer likes or dislikes about their current phone.

That text is then cleaned and functions defined in step 2 is applied.

From this data create a data mart

Then map these words to the phone that this words relate to

For creating a word cloud, create a corpus from the existing data mart that has been obtained.

- Finding tweets for the phones in the data and cleaning them

For crawling twitter create an access token[9].

Using predefined methods provided by API connect to Twitter to pull tweets into dataset.[6]

Similar to dataset iterate the data set. Identify each and every phone and traverse the internet to fetch the information regarding each phone.

In this use the predefined positive and negative words library that is loaded in the environment.

- Finding positive and negative words in $\mathbf{R}$ studio For finding positive words and negative word in $\mathrm{R}$ studio there is a lexicon predefined for this purpose. Take the words from the sentence or phrase to process and then match each of those word to the one present in the lexicon.

Before matching the word, it would need some cleaning to get the optimum result.

- Displaying them in graphs and charts

For displaying the result 2 graphical representation is used

a. Word cloud - displaying words in the size of their frequency so that the word with most importance rise to the surface.

b. Bar chart - Traditional bars of data indicating the frequency of information present in that group.

\subsection{Implementation finding}

\subsubsection{Basis}

The target customer is of following profile

- Age between 25 and 40

- Gender Male

- Currently qualified as a graduate

- Is currently employed.

On the basis of this target customer nearest 40 neighbours were taken from the data set based on distance.

The result set was then trimmed to take the columns that would be used for further processing.

This targeted result set was then traversed and step 3, 4 and 5 was applied to get the transformed data.

In step 5 for each phone maximum 100 tweets (the result may be less in certain cases) were requested from twitter.

\subsubsection{Findings}

1. How to approach the customer?

Table 1: Customer shopping details

\begin{tabular}{|l|l|}
\hline Medium & Count \\
\hline Got it as a gift & 1 \\
\hline Offline shopping & 14 \\
\hline Online shopping & 25 \\
\hline
\end{tabular}

The indication that users mainly look into online shopping for tech products rings true. More and more working place people don't have time to go to shops. Although offline shopping is not far behind in this market yet.

In this online market where do customer look for recommendations

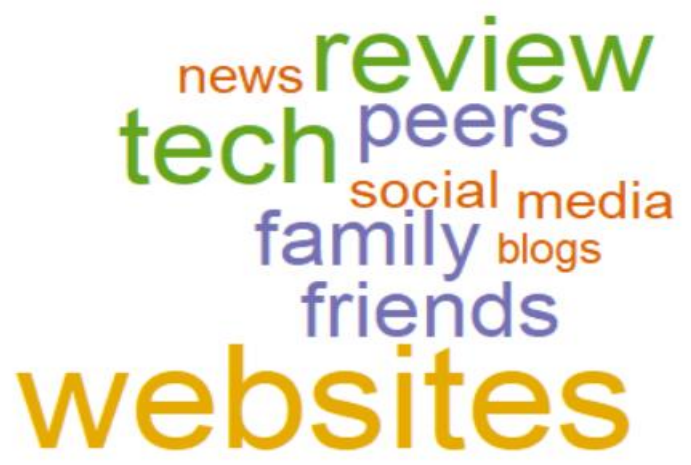

Figure 2: Online review places

As the image above suggests people look for tech reviews and website (techgeek, android blog) etc. for feedback. Online presence of company is necessary for making impact.

2. The phones which this customer base uses the most are? Table 2: Popular phones

\begin{tabular}{|l|l|}
\hline Phone & Count \\
\hline Moto G4 plus & 4 \\
\hline OnePlus 3T & 3 \\
\hline Other & 2 \\
\hline Nokia 6 & 2 \\
\hline OnePlus 3 & 2 \\
\hline Samsung Galaxy S8 & 2 \\
\hline
\end{tabular}

The range of phones in this range from mid to flagship phones. This shows even though people want affordable phones, they do not compromise much on performance.

\section{What do people think about their phone?}

The features that people like about their phone are the camera, processing, performance and aesthetics. This shows the usage pattern of people. Social media and other application which require high processing and camera to share moments has taken central role on social usage of phone. 


\section{performance processor

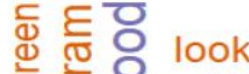 \& O quality camera}

\section{Figure 3: Positive features about phones}

The feature they hate about phone are related to battery and overheating of phone. This makes the usage of phones more difficult and the main point of carrying phone is moot if the battery does not have good lifetime.

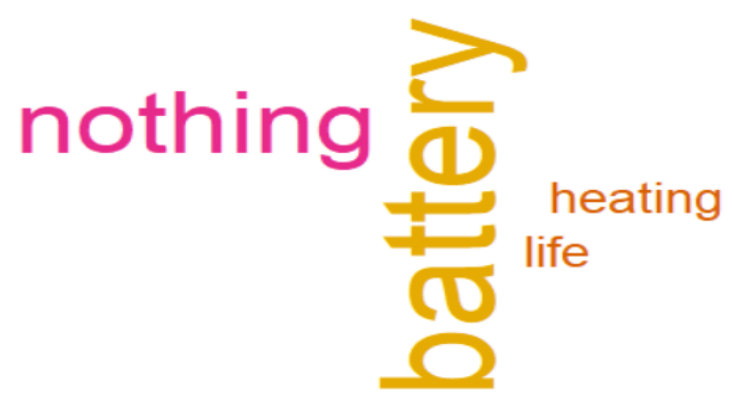

Figure 4: Negative features about phones

4. What features that people desire in a phone ideally? The features ideally people want in their phones are dual lens camera, quick charging ability and multitasking ability. These are the new features that are present in all the flagship phones now demonstrating that phones have become more of social standard than ever.

\section{quickuch|lergincanbira}

\section{Figure 5: Ideal phone features}

5. How much are the customer willing to splurge for a phone?

The ideal price range for customer is $10 \mathrm{k}$ and $25 \mathrm{k}$. This shows that even though people expect all the features on a mobile phone the price of the phone cannot range more than an average phone. This becomes a bottleneck to introduce new features on the phone. If the phone is not worth it this makes a huge impact on decision making of people as they look for cheap alternative always.
Table 3: Phone price ranges

\begin{tabular}{|l|l|}
\hline Price range & Count \\
\hline Between 10001-25000 & 26 \\
\hline Between 25001-60000 & 7 \\
\hline Between 5001-10000 & 6 \\
\hline Above 60001 & 1 \\
\hline
\end{tabular}

6. What is performance of the phone flagships individually?

The performance of phones based on flagship

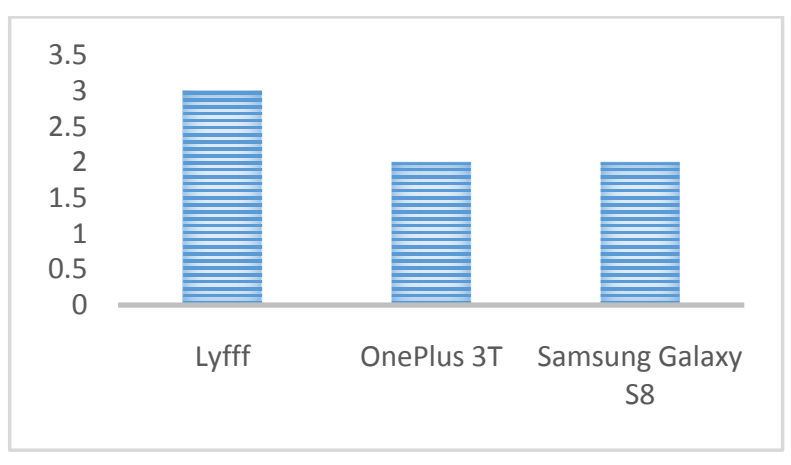

Figure 6: Best performing flagships

Lyfff, Oneplus 3t, Samsung galaxy S8 have got good rating scale as they meet the peoples' requirements stated above.

The flagship with most negative feedback is Oppo neo 7 which maybe because of price to performance ratio of it being poor and it does not have any feature mentioned above.

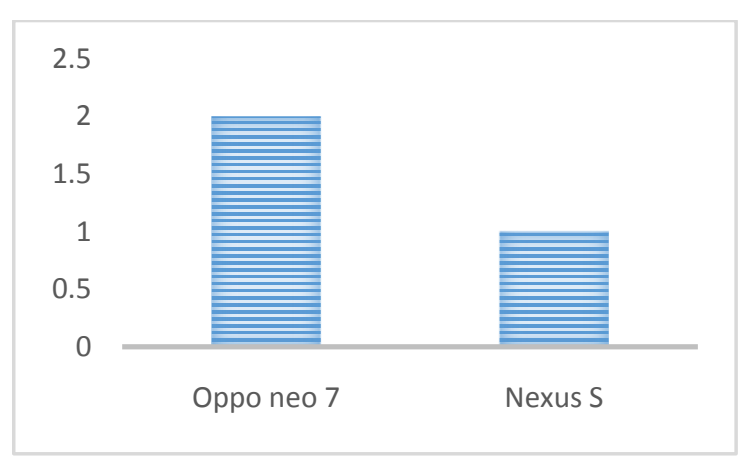

Figure 7: Worst performing flagships

7. How does opinion of people on Twitter line up with our respondents in our survey?

All this feedback is from the sources that is known i.e. survey. Now for unknown sources scour twitter for information regarding the phones and what others think about these same flagship devices. 


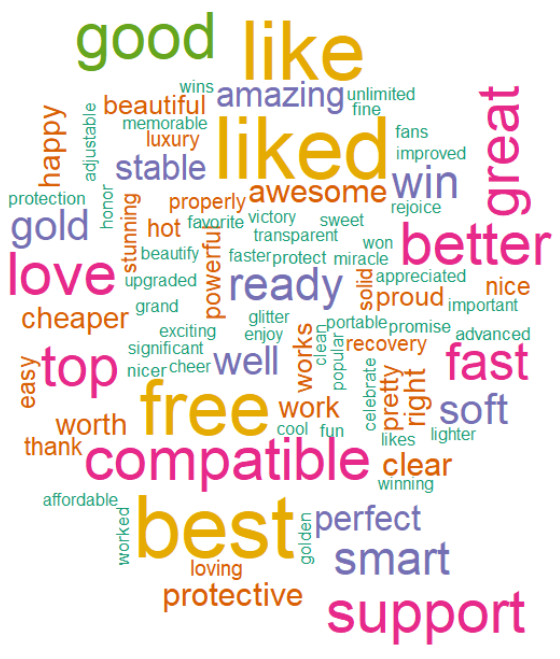

Figure 8: Positive phone feedback

There is stark contrast in these feedback. One being specific(survey) while other being vague(twitter) because of its openness. Although it's clear that people want their phone to be easy to use and accessible all the time. This defines the basic needs of all the mobile phones.

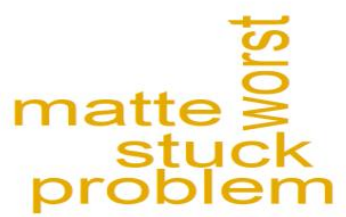

Figure 9: Negative phone feedback

The worst problem people face mobile phone is they get stuck using it or face some problem comprehending the feature. This means ease of use is the most requested feature users want on their phone. On top of that aesthetics plays a large role in social settings, so equal amount of attention must be paid to that too.

The high performing phones in this category are Honor $7 \mathrm{x}$, Moto GPlus and Samsung j7 prime

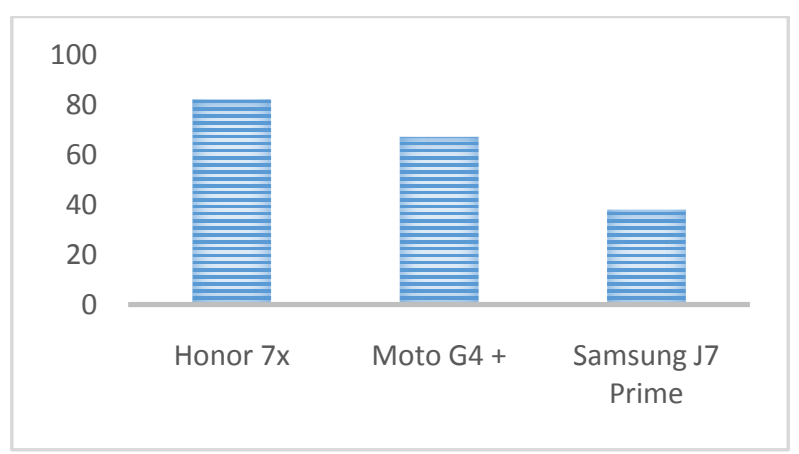

Figure 10: Best phone brands

\section{Conclusion}

From this study it can be concluded that for this target audience the phone that suits are having
i. $\quad$ Priced between 10k INR. (Indian Rupees) and 25k INR.
ii. $\quad 3500 \mathrm{mAh}$ battery
iii. 5 inches' screen with minimum top and bottom bezel
iv. $3 \mathrm{G} / 4 \mathrm{G}$ support
v. 8 Megapixel camera, preferably with dual lens camera
vi. LED screen
vii. Less bloatware (pre-installed applications)
viii. IP 67 Enclosure (Dust tight and water resistant) ix. Button less phone

\section{CONCLUSION AND FUTURE SCOPE}

The conclusion from the study will allow the company to take decision on the results of the data. The volatility of the market allows the company to gauge the changes before committing to a product. This will also reduce the capital expenses of company has to bear to create the product.

This study conducted shows the various ways of achieving this. The sample used in this study can be skewed and thus cannot be used without scrutiny.

This study uses anonymous data for tackling the data protection crisis that is rampant in all over digital world. It would be useful to use both the unreliable and reliable data for their work if company is not able to find huge amount of reliable data.

The ideal method to use known/unknown media would be to do the survey on the basis of unknown media feedback. This would serve two purpose

- It would discover new dimension to query

- It would reduce the gap between known and unknown media

If the known and unknown media is giving us the same feedback, then it's consistent and can be accepted. In the case it varies the process should be repeated to see how much discrepancy is there in both the media result. If it is not reducing the gap, then there is some problem and the study should start over with different premise again.

The overall output of the combination of known/unknown media would require some weightage method to determine the impact it has in the final output. It is dependent on case by case basis.

The future scope for this study includes various sources of information, information management, some algorithms to crawl through data and analyse some fake information that is being spread through the grapevine communication that is Word of Mouth.

Apart from this scenario considered the scope of the application can be increased to make the process of innovation and creating new ideas efficient and more economic.

\section{REFERENCES}

[1] Word of Mouth and its impact on marketing, Fatima Naz https://www.google.co.in/url?sa=t\&rct=j\&q=\&esrc=s\&s ource $=$ web $\& c d=1 \& c a d=$ rja $\& u a c t=8 \& v e d=0 a h U K E w j c$ v2y-

pDXAhVFpo8KHeT4DA0QFgglMAA\&url=http\%3A\% 
2F\%2Fwww.ijsrp.org\%2Fresearch-paper-0114\%2Fijsrpp25121.pdf\&usg=AOvVaw1fkYJm9hkr69nnLUuy9eE-

[2] Digital Word of Mouth Marketing: Perspectives and Challenges, Mrinmoy Kumar Sarma1, Professor, Sandeep Kumar Singh2, Senior Research Fellow, Business Administration, TEZPUR UNIVERSITY.

[3] An empirical study of online Word of Mouth as predictor for multi-product category and e-Commerce sales https://dl.acm.org/citation.cfm?id=1451510

[4] Barclay, I., Dann, Z., Holroyd, P. (2001). New Product Development. London: Routledge.

[5] R studio https://www.rstudio.com/

[6] Twitter $\mathrm{R}$ package https://cran.rproject.org/web/packages/twitteR/twitteR.pdf

[7] R Studio distances package https://cran.rproject.org/web/packages/distances/distances.pdf

[8] Twitter access token and API key https://developer.twitter.com/en/docs/basics/authenticatio $\mathrm{n}$ /guides/access-tokens.html

[9] A framework for successful new product development http://www.jiem.org/index.php/jiem/article/viewFile/334/ 240
[10] Developing a new product development \& lunch process Case: Company X https://www.theseus.fi/bitstream/handle/10024/72281/Th esis\%20FP\%20Theseus\%20-Jonis.Mahmutllari1004417.pdf?sequence $=1$

[11] Impact of Word of Mouth on Consumer Buying Decision https://www.researchgate.net/profile/Nawaz_Ahmad3/pu blication/267631614_Impact_of_Word_of_Mouth_on_C onsumer_Buying_Decision/links/5454fa1a0cf2bccc490c c6f9/Impact-of-Word-of-Mouth-on-Consumer-BuyingDecision.pdf

[12] Word of Mouth Behavior and Online Activity: A Study of On/Off Line Communication Strategy and Online Business https://www.insper.edu.br/en/wpcontent/uploads/2013/12/2011_wpe263.pdf

[13] Richins, Marsha L. "Negative Word-of-Mouth by Dissatisfied Consumers: A Pilot Study." Journal of Marketing, vol. 47, no. 1, 1983, pp. 68-78. JSTOR, JSTOR, www.jstor.org/stable/3203428.

[14] Jacqueline Johnson Brown, Peter H. Reingen; Social Ties and Word-of-Mouth Referral Behavior, Journal of Consumer Research, Volume 14, Issue 3, 1 December 1987, Pages 350-362, https://doi.org/10.1086/209118 